\title{
Crítica (de arte) y teoría crítica
}

\author{
Art criticism and critical theory
}

\author{
Miguel Cereceda Sánchez \\ Universidad Autónoma de Madrid. \\ miguel.cereceda@uam.es
}

DOI: http://doi.org/10.15366/bp2019.21.012

Bajo Palabra. II Época. No21. Pgs: 199-220 


\section{Resumen}

Intento de mostrar cómo la crítica artística y literaria es el modelo de la concepción crítica de la filosofía, característica del pensamiento de Kant, de Marx y de la Teoría crítica de Adorno y Horkheimer.

Palabras Clave: Critica artística y literaria, Teoría crítica, Filosofía y critica, criticismo, Kant, Marx, Adorno, Horkheimer.

\section{Abstract}

Attempt to show how artistic and literary criticism is the model of the critical conception of philosophy, a characteristic conception of the thought of Kant (known as criticism), Marx and of the Critical Theory of Adorno and Horkheimer.

Keywords: Art criticism, Critical Theory, Philosophy, Kant, Marx, Adorno, Horkheimer. 
$\mathrm{M}$ ax Horkheimer nos dejó básicamente dos textos en torno a las características propias de la Teoría crítica, frente a la teoría tradicional. El primero es de 1937, y fue escrito en el exilio, en los Estados Unidos. En él se defiende que, lo que diferencia a la teoría crítica de la tradicional es la comprensión de que el sujeto del conocimiento no es algo separado del objeto conocido, y de que este conocimiento está a su vez determinado por la lucha de clases y el carácter social. En este sentido, la Teoría crítica no se limita a ser objetiva, sino que tiene que tomar partido. "Aunque la Teoría crítica — escribe Horkheimeren ningún momento procede arbitrariamente o por azar, para el modo dominante de juzgar ella aparece, justamente por eso, como subjetiva y especulativa, parcial e inútil» ${ }^{1}$.

El segundo texto son unas conferencias impartidas en Venecia en 1969. Horkheimer esperaba poder encontrarse allí con su amigo Theodor Adorno, pero Adorno acababa de fallecer durante unas vacaciones en Suiza ese mismo verano. En estas conferencias, transcritas sin la revisión del autor, Horkheimer reconoce aquellos aspectos del marxismo que considera históricamente equivocados, renuncia explícitamente a la revolución, "porque la revolución se convertiría de nuevo en un terrorismo" "; y termina reconociendo también algunos de los valores positivos de la religión. Tal vez por eso, para Horkheimer, en este sentido "la Teoría crítica tiene la misión de expresar lo que en general no se expresa" ${ }^{3}$.

Más de cien años antes, Charles Baudelaire publicaba una serie de reseñas del Salón de 1846, en las que hablaba del romanticismo, del color o de Eugène Delacroix, precedidas de un breve texto sobre la crítica de arte, titulado "A quoi bon la critique?”, en el que defendía que la mejor crítica es amena y poética, que la mejor crítica de un cuadro debería ser tal vez un soneto o una elegía. Pero que esta crítica estaría destinada en su opinión más bien a los libros de poesía y por eso, en cuanto a la "crítica" propiamente dicha, Baudelaire afirmaba lo siguiente:

\footnotetext{
1 Max Horkheimer, "Teoría tradicional y teoría crítica" (1937), en Teoría crítica, trad. de Edgardo Albizu y Carlos Luis, Amorrortu Editores, Buenos Aires, Madrid, 1974, tercera reimp. 2003, p. 250.

2 Max Horkheimer, "La teoría crítica, ayer y hoy", en Sociedad en transición: estudios de filosofía social, trad. de Joan Godó Costa, Península, Barcelona, 1976, p. 59.

3 Id. p. 65.
} 
Espero que los filósofos comprenderán lo que voy a decir: para ser justa, es decir, para tener razón de ser, la crítica ha de ser parcial, apasionada, política, es decir, hecha desde un punto de vista exclusivo, pero desde el punto de vista que abra el máximo de horizontes ${ }^{4}$.

Siguiendo a Baudelaire, yo también espero que los filósofos me comprendan y, según esto, la tesis que a continuación quisiera desarrollar es la de que la llamada Teoría crítica y, en general, toda concepción crítica de la filosofía toma su modelo de la crítica artística y literaria, y no al revés.

Si uno le echa una ojeada al artículo "Critique" de la Encyclopédie de D’Alembert y Diderot, escrito en 1751 por Marmontel, lo que ahí se encuentra es que la primera referencia a la crítica está siempre sacada o tomada de la crítica literaria. Y así la crítica se aplica, según él, en primer lugar, a la restitución de la literatura antigua. "Crítica" es entonces, la filología, la exégesis y la erudición. Esta crítica puede aplicarse también a los escritos sagrados, respetando, dice Marmontel, el carácter revelado de los mismos. Del mismo modo, podrá aplicarse también a los descubrimientos de la ciencia y a los acontecimientos históricos. Pero sin lugar a dudas, para él la crítica es con preferencia la crítica literaria. Después de ella, podrán venir también la crítica de la arquitectura y de la música, la crítica de la escultura y de la pintura. Y a partir de ellas también la crítica moral y política. Pero, para Marmontel y para los enciclopedistas en general, el modelo de crítica es siempre la crítica literaria. "Por muchas que sean las dificultades que presente la crítica de arte - escribe- ni siquiera se acercan a las que reúne la crítica literaria" ${ }^{5}$. De hecho, para él, "el modelo intelectual según el cual un crítico superior juzga la Moral y la Elocuencia entra esencialmente en el modelo al que debe remitirse la Poesía"

Pues bien, la tesis que según esto pretendo desarrollar es la de que:

1. La Estética es la disciplina que pretende establecer y fundamentar una verdadera teoría de la crítica. Es decir, una crítica como ciencia.

2. Este intento va a ser desarrollado, a partir de Alexander Baumgarten, sobre todo por Kant, en su Crítica del Juicio, de 1790.

\footnotetext{
${ }^{4}$ Charles Baudelaire, “¿Para qué la crítica?”, Salón de 1846, en Salones y otros escritos sobre arte, trad. de Carmen Santos, Visor, Madrid, 1996, p. 102.

5 Denis Diderot et Jean le Rond d'Alembert, Encyclopédie, ou Dictionnaire raisonné des sciences, des arts et des métiers, s/v. "Critique ", primera edición París, 1751, Tomo 4, pp. 489-497.

${ }^{6}$ Id.
} 
3. En la obra de Kant, la crítica (artística y literaria) se convierte en el modelo de la filosofía.

4. Este modelo crítico será el elaborado por Marx y Engels en la construcción de su propio modelo de crítica social y política.

5. Por ello finalmente, en Adorno y en Horkheimer, los padres de la Teoría crítica, es tan decisiva y tan importante la Estética, la crítica literaria y la crítica musical, como la crítica filosófica y política. De hecho, son, para ellos, la misma actividad.

\section{Estética y crítica}

Como es sabido, es Alexander Baumgarten el fundador de la Estética como disciplina académica.

Casi al principio de su Estética (1750-1758), Baumgarten examina algunas posibles objeciones contra esta nueva disciplina. Una de ellas es que posiblemente el contenido de la Estética no sea nada nuevo ni nada diferente del de la Retórica y la Poética. Objeción a la que responde que la Estética se complementa con otras artes y que su estudio permitirá a cada una de estas disciplinas cultivar su propio terreno, sin tautologías inútiles. Pero la siguiente objeción que él mismo se pone es que, al parecer, tampoco hay gran diferencia entre la Estética y la Crítica. Esta objeción resulta particularmente interesante, porque establece una relación de identidad entre Estética y Crítica. Veámosla, con las propias palabras del filósofo:

\$5. 3.- eadem esse cum critica. Resp. a) est etiam critica logica, b) quaedam critices species est pars aesthetices, c) huic praenotio quaedam aesthetices reliquae paene necessaria est, nisi velit in diiudicandis pulchre cogitatis, dictis, scriptis disputare de meris gustibus ${ }^{7}$.

\$5. 3.- es lo mismo que la crítica. Respondo: a) también hay una crítica lógica; b) un cierto tipo de crítica es parte de la estética; c) es necesaria una cierta prenoción de la estética si no se quiere disputar de meros gustos a la hora de juzgar la belleza de los pensamientos, los dichos y los escritos.

Que la Estética sea entonces lo mismo que la Crítica no es por tanto objeción alguna, si se hacen algunas matizaciones. Y la primera es que no sólo hay una crítica estética, sino también una crítica lógica. Pero que, en cualquier caso,

${ }^{7}$ Alexander Gottlieb Baumgarten, Aesthetica, Traiecti cis Viadrum (Frankfurt del Oder), 1750, $\$ 5$. 
un cierto tipo de crítica es parte de la Estética. Y, además, esta parte crítica es necesaria, si no se quiere disputar de meros gustos. ¿A qué crítica se refiere aquí Baumgarten?

En su Metafísica - publicada en 1739, pero muy reelaborada en su tercera edición de 1750 - nos proporcionaba Baumgarten una definición general de este concepto: "Critica latissime dicta est ars diiudicandi" ("La crítica en el sentido más amplio es el arte de juzgar"). Y a continuación define el concepto de crítica estética como: "ars formandi gustum seu de sensitive diiudicando et iudicium suum proponendo" ("El arte de formar el gusto o de juzgar acerca de lo sensible proponiendo su propio juicio" $)^{8}$. En consecuencia, la crítica estética se distingue para él de la crítica en general, en su relación especial con el gusto y con el juicio.

Y todavía, en un manuscrito sobre la Estética que no se publicó hasta 1907, afirmaba lo siguiente:

La Estética va mucho más allá que la Retórica y que la Poética y no es idéntica a ellas. Mucho menos es idéntica a la Crítica. Cuando quiero juzgar un escrito, una pintura o una música con claridad (nach Deutlichkeit), allí tiene que haber una teoría. Esta teoría sin embargo no es nunca la crítica misma, si a partir de ella me quiero servir de la crítica. Cuando juzgo, no debo hacerlo solamente según mi gusto, sino que tengo que juzgar con claridad. La Estética va mucho más allá que la Crítica, pues puede ser utilizada para muchas más cosas que para juzgar. La relación será correcta si, tal como la Lógica es a la Lógica crítica, se considera a la Estética en general respecto de la Estética crítica ${ }^{9}$.

En consecuencia, aunque la crítica no se identifica plenamente con la Estética, hay sin embargo entre ellas una intensa relación, que parece llevarlas a una cierta confusión. Para Baumgarten la Estética no es solamente crítica, pues esta disciplina tiene otros usos que no tienen que ver con la crítica y, por tanto, es una disciplina mucho más extensa. Por ejemplo, para él, uno de los usos posibles de esta nueva disciplina es el de poner el conocimiento científico al alcance de cualquiera. Ello nada tiene que ver con la crítica, sino si acaso con la hermenéutica o con la exégesis. Y por eso, aunque una cierta parte de la Estética se identifica con la crítica, sin embargo, no se agota en ella.

Sea como fuere, a partir de la fundación de la Estética como disciplina académica, se produjo una cierta confusión e identificación entre Estética y crítica, confu-

\footnotetext{
${ }^{8}$ Alexander Baumgarten, Metaphysica, Halae Magdeburgicae (Halle), 3a Ed., 1750, $\$ 607$.

${ }^{9}$ El llamado Vorlesungsnachschrift fue publicado por primera vez por Bernhard Poppe en su libro Alexander Gottlieb Baumgarten: Seine Bedeutung und Stellung in der Leibniz-Wolffischen Philosophie und seine Beziehungen zu Kant: Nebst Veröffentlichung einer bisher unbekannten Handschrift der Ästhetik Baumgartens, Robert Noske, Borna-Leipzig, 1907; $\$ 5$, p. 75.
} 
sión que la hace filosóficamente fértil, en tanto que, precisamente a partir de Kant, la filosofía se convierte a sí misma en filosofía crítica.

La transformación de la filosofía en crítica se corresponde con un momento específico de la historia de la propia filosofía. Cuando Aristóteles define la filosofía, la describe como ciencia de los primeros principios y de las primeras causas de las cosas $^{10}$. Para él es importante caracterizar lo propio de la sabiduría y en este sentido la ciencia que se busca, a la que denomina Sofía, es la más universal, la más general, la más escible y la que se ocupa de los primeros principios y de las primeras causas de las cosas. No hay aquí crítica de ningún tipo. Tampoco la hay en Tomás de Aquino, para el que la filosofía admite las contradicciones y las objeciones de la razón contra la doctrina de la fe, pero considera abiertamente que la filosofía tiene que llegar por sus medios a las mismas certezas a las que lleva la revelación ${ }^{11}$.

Tomás de Aquino ya no habla de Sofía, sino de Sapientia, y define la sapientia como conocimiento de lo divino ("sapientia dicitur esse divinorum cognitio") ${ }^{12}$. Y tiene en cualquier caso claro que "aun cuando los argumentos de razón no sean capaces de poder probar lo que es de fe, sin embargo, la doctrina sagrada, partiendo de los artículos de fe, puede deducir otras verdades de fe" ${ }^{13}$. Ello desde luego no le exime de una actitud crítica, a la hora de criticar las diversas opiniones, pero es evidente que para él no todo está absolutamente en cuestión. "La metafísica, que es la suprema de las ciencias filosóficas, discute contra quien niega sus principios siempre que éste esté de acuerdo en algo; pues si el interlocutor lo niega todo, a la metafísica no le es posible discutir con él, aunque sí puede resolver sus problemas" ${ }^{14}$.

Es posible que la actitud crítica aparezca en filosofía con el método de Descartes, pues él es el primero que admite no dar nada por supuesto hasta que no sea demostrado de un modo claro y evidente. En Descartes se produce una inversión del pensamiento, consistente en examinar antes el modo de conocer que el objeto conocido. El Discurso del método, las Meditaciones metafísicas y las Regulae ad directionem ingenii, no son más que otros tantos intentos de examinar la capacidad cognitiva antes que ponerse a discutir de los objetos conocidos. En este sentido es posible que la duda metódica haya sido la principal aportación del pensamiento

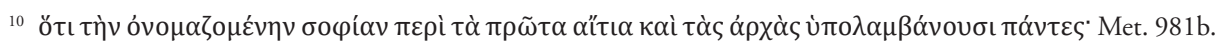

11 "A diversos modos de conocer, diversas ciencias. Por ejemplo, tanto el astrónomo como el físico pueden concluir que la tierra es redonda. Pero mientras el astrónomo lo deduce por algo abstracto, la matemática, el físico lo hace por algo concreto, la materia. De ahí que nada impida que unas mismas cosas entren dentro del campo de las materias filosóficas siendo conocidas por la simple razón natural y, al mismo tiempo, dentro del campo de otra ciencia cuyo modo de conocer es por la luz de la revelación divina”. Summa Theologiae, Ia q. 1 a. 1 ad 2

12 Summa, Ia q. 1 a. 6 co

13 Summa, Ia q. 1 a. 8 ad 1

${ }^{14}$ Ia q. 1 a. 8 co
} 
cartesiano, aunque también es cierto que esta duda es heredera de un escepticismo católico que se enfrentaba abiertamente al protestantismo, poniendo precisamente en duda la capacidad de la razón de llegar por sí misma a entender e interpretar las "verdades reveladas" en la escritura. "Crítica" ya era por tanto la actitud de Lutero frente a la autoridad del Papa, pues la defensa protestante de la "sola Scriptura" y del libre examen establecían los fundamentos de una nueva actitud racionalista, actitud a la que se opuso activamente el escepticismo católico de finales del s. XVI.

\begin{tabular}{|l|c|c|}
\hline Lutero & Tesis de Wittenberg & 1517 \\
\hline Concilio de Trento & & $1545-1563$ \\
\hline Matanza de San Bartolomé & & 1572 \\
\hline Francisco Sánchez & De que nada se sabe & 1581 \\
\hline Montaigne & Ensayos & $1580-1595$ \\
\hline Edicto de Nantes & & 1598 \\
\hline Pierre Charron & De la sagesse & Bordeaux 1601 \\
\hline Descartes & Discurso del método & 1637 \\
\hline
\end{tabular}

Por ello el pensamiento cartesiano no es tan novedoso ni en su crítica sistemática del conocimiento ni en su rehabilitación posterior, casi automática, de todos los grandes dogmas de la fe católica: la existencia de un alma inmortal y la existencia de Dios. El hecho históricamente documentado de que Descartes planease peregrinar al santuario de la virgen de Loreto, en agradecimiento por sus hallazgos filosóficos, es una buena muestra de esta actitud ${ }^{15}$ : la de la filosofía al servicio de la superstición. Pues la tradición quiere que el santuario de la virgen de Loreto en Italia se construyera en torno a la casa donde la virgen María recibió la sombra del Espíritu, casa que había llegado allí prodigiosamente por los aires, desde Croacia, a donde había sido llevada a su vez por los cruzados. Tal vez por ese motivo Fontenelle trató de distinguir cuidadosamente entre el método cartesiano y sus aportaciones filosóficas, la mayor parte de las cuales, en su opinión, "eran falsas o bastante inciertas, según las propias reglas que él nos había enseñado" 16 .

15 El 19 de abril de 1620 Descartes dejó escrito en sus cuadernos su propósito de peregrinar a Loreto antes de noviembre de ese mismo ańo. No hay sin embargo constancia documental de que Descartes cumpliera su promesa. Desmond M. Clarke, Descartes, A Biography, Cambridge University Press, 2006, p. 64.

16 " Avant M. Descartes on raisonnait plus commodément; les siècles passés sont bienheureux de n’avoir pas eu cet homme-là. C'est lui, à ce qu'il me semble, qui a amené cette nouvelle méthode de raisonner, beaucoup plus estimable que sa philosophie même, dont une bonne partie se trouve fausse, ou fort incertaine, selon les propres règles qu'il nous a apprises. Enfin il règne non seulement dans nos bons ouvrages de physique et de métaphysique, mais dans 
En cualquier caso, tanto su pensamiento científico como su método, así como sobre todo la enorme influencia que este pensamiento tuvo en toda Europa, no admiten dudas con respecto a la importancia de su filosofía y de la relevancia de su actitud crítica. La filosofía cartesiana está entonces así a la base del pensamiento de Leibniz, del pensamiento de su discípulo y sistematizador Christian Wolff, e igualmente a la base del pensamiento del discípulo de este, padre de la Estética, Alexander Baumgarten.

\section{„Unser Zeitalter ist das eigentliche Zeitalter der Kritik“}

LA FILOSOFÍA DE KANT viene a ser la culminación de la actitud crítica de la Ilustración. No en vano su obra fundamental asume el nombre de crítica no sólo como título de sus libros, la Crítica de la razón pura, la Crítica de la razón práctica y la Critica del Juicio, sino también como programa general de su filosofía. El criticismo es también el otro nombre que Kant le dio a su propia filosofía.

No es mi intención aquí hacer el estudio sistemático de los distintos usos que la palabra crítica tiene en la filosofía kantiana, aunque sí que quisiera mostrar cómo para él la crítica se identifica en general con la filosofía. Al respecto los dos prólogos que Kant publicó para su Crítica de la razón pura, el de la primera y el de la segunda edición, son de una utilidad inestimable.

En el primero de estos prólogos, Kant se plantea el problema general de la filosofía como un campo de batalla de inacabables disputas. Frente a tales disputas, es cierto que cabe también el desdén y la indiferencia. Pero curiosamente esta indiferencia no es el producto para él de una ligereza, sino más bien de una época que ya no se contenta con un saber aparente. "Nuestra época —escribe Kant en una nota- es de modo especial la de la crítica. Todo ha de someterse a ella. Pero la religión y la legislación pretenden de ordinario escapar a la misma. La primera a causa de su santidad y la segunda a causa de su majestad. Sin embargo, al hacerlo, despiertan contra sí mismas sospechas justificadas y no pueden exigir un respeto sincero, respeto que la razón sólo concede a lo que es capaz de resistir un examen público y libre" ${ }^{17}$.

Es por eso necesario establecer un tribunal que pública y libremente determine, de una vez por todas, el alcance y los límites de la razón. "Semejante tribunal no es

ceux de religion, de morale, de critique, une précision et une justesse qui jusqu’à présent n'avaient été guère connues ". Bernard le Bovier de Fontenelle, "Digression sur les anciens et les modernes" (Paris, 1688) en Robert Shackleton, ed., Entretiens sur la pluralité des mondes et Digression sur les anciens et les modernes, Oxford, 1955, pp. 161-176.

${ }_{17} \mathrm{KrV}$, A XII; trad. Pedro Ribas, Alfaguara, Madrid, 1984, p. 9. 
otro que la misma Crítica de la razón pura" ${ }^{18}$. De este modo la Crítica de la razón pura se presenta a sí misma como un tribunal que la razón establece para juzgarse a sí misma, y en el que la propia razón se presenta como juez, fiscal, abogado defensor y reo.

Con independencia de los problemas y las contradicciones en que esta posición autorreferente de la razón pueda incurrir, esta actitud crítica todavía se presenta en el primer prólogo como seguidora de los criterios cartesianos, de claridad y distinción. Pues a una crítica semejante Kant le exige completud (Vollständigkeit) y exhaustividad (Ausführlichkeit), así como certeza (Gewißheit) y claridad (Deutlichkeit).

Por su parte el segundo prólogo, o prólogo a la segunda edición, publicado en 1787, se plantea el problema general de cómo podría la filosofía alcanzar el camino seguro de la ciencia. Pues es evidente que hay ciencias en las que los especialistas ya no se enredan en disputas sin término, como la lógica, la matemática, la geometría o la física, que han encontrado un camino seguro y que ya no avanzan a tientas. En cambio, "la metafísica — escribe Kant, en este segundo prólogo — no ha tenido hasta ahora la suerte de poder tomar el camino seguro de la ciencia" ${ }^{19}$. En ella la razón se atasca continuamente y parece más bien un campo de batalla (ein Kampfplatz). También en esto se muestra Kant como un perfecto cartesiano, recordando las quejas de Descartes contra la filosofía, en la primera parte de su Discurso del método ${ }^{20}$. Y para ponerle remedio a esta situación, Kant se propone seguir en metafísica el mismo modelo de las ciencias y, según él, "este ensayo obtiene el resultado apetecido y promete a la primera parte de la metafísica el camino seguro de la ciencia" ${ }^{21}$.

De este modo, el problema general que aborda Kant en la Crítica de la razón pura es el de cómo es posible, si es que es posible, una metafísica como ciencia. Por Metafísica entiende Kant lo que, desde Aristóteles entiende toda la tradición filosófica: la filosofía primera o la ciencia de los primeros principios y de las primeras causas de las cosas. Sin embargo, el uso especial que hace de este concepto y su fundamentación sobre bases enteramente nuevas han llevado a numerosas disputas acerca del sentido y el alcance de sus logros filosóficos. De hecho, todavía

\footnotetext{
18 Ibid.

$19 K r V$, B XIV; trad. p. 19.

20 "Nada diré de la filosofía, pero sí haré constar la impresión que en mi ánimo produjo. Al ver que la habían cultivado las inteligencias más preclaras y a pesar de ello nada quedaba fuera de discusión, libre de duda (...), consideré las innumerables opiniones de los sabios, vi que todas ellas se encuentran con frecuencia muy lejos de la verdad y desde aquel momento creía falso o poco menos todo lo que se presentaba a mi inteligencia aun con el carácter de verosímil”. René Descartes, Discurso del método, Primera parte, trad. de Manuel Machado, Porrúa, Argentina, 1974, p. 11.

${ }^{21} K r V$, B XVIII; trad. p. 21.
} 
hay quien piensa que, en la obra de Kant, se produce una superación crítica de la metafísica, para afirmar solamente la posibilidad del conocimiento científico experimental, entendiendo toda la Crítica de la razón pura como una especie de teoría del conocimiento. Esta opinión, característica de la llamada escuela de Marburgo, fue duramente criticada por Martin Heidegger, en 1929 en Davos, en un sonado enfrentamiento con Ernst Cassirer, así como en su libro Kant y el problema de la metafisica, publicado ese mismo año.

Para saber cómo es posible, si es que es posible, la Metafísica como ciencia, Kant va a explorar las condiciones de posibilidad de las otras ciencias. Cómo son posibles las matemáticas y la geometría como ciencias, y cómo es posible la física newtoniana como ciencia son preguntas que le sirven como una especie de hilo conductor, para plantear las condiciones de posibilidad de una metafísica científica, en la que ya no nos veamos arrastrados a disputas sin cuento.

Kant sugiere que, lo que las matemáticas y la geometría conocen a priori del mundo, está puesto en realidad por nuestro modo de percibir el mundo, y que lo que la física conoce a priori del mundo está puesto por nuestro modo de entender el mundo. Por ese motivo estudia las condiciones de posibilidad de las matemáticas y la geometría como ciencias, en el contexto de una teoría general de la sensibilidad, y las condiciones de posibilidad de la física como ciencia, en el contexto de una teoría general del entendimiento. A la primera, siguiendo el uso etimológico del término, la denomina Estética trascendental y a la segunda, Lógica trascendental.

Es en realidad esta Estética trascendental la que a nosotros nos interesa como ciencia. En ella Kant no se va a ocupar ni de la belleza ni de la sublimidad, ni de la clasificación de las artes, ni tampoco del criterio del gusto. Por el contrario, nos encontramos aquí una sorprendente doctrina acerca del espacio y del tiempo, según la cual se establece que el espacio y el tiempo son las formas puras a priori de la sensibilidad. No son entidades absolutas existentes en sí y por sí, sino nuestro modo de percibir el mundo. Kant denomina al espacio la forma pura a priori de la sensibilidad externa, y al tiempo la forma pura a priori de la sensibilidad interna.

¿Cómo es posible la geometría como ciencia? Pues es posible porque resulta que lo que nosotros conocemos en ella a priori del mundo es precisamente lo que nosotros ponemos a priori en nuestro modo de percibir el mundo. En este caso, la forma pura a priori de la sensibilidad externa, que es el espacio.

Lo mismo sucede con respecto al tiempo, como fundamento de las matemáticas. Kant denomina al tiempo la forma pura a priori de la sensibilidad interna y considera que la matemática es posible como ciencia, porque su forma general, la del número y su sucesor, se funda en la forma general de la temporalidad (lo primero, lo segundo, lo tercero, etc.), que es universal y común a todos los hombres. Por 
tanto, lo que conocemos a priori en matemáticas y en geometría es aquello mismo que nosotros ponemos a priori en nuestro modo de percibir el mundo.

Kant denomina Estética trascendental a esta doctrina general de la sensibilidad en la que se estudian las condiciones de posibilidad de las matemáticas y de la geometría como ciencias. Aquí la Estética no se ocupa en absoluto de la doctrina de las artes liberales, de la belleza y de la fealdad, o de nuestros juicios de gusto. La Estética en este caso es una ciencia, cuyo contenido son las formas puras a priori de la sensibilidad. Kant desdeña el uso tradicional del término, propuesto por Baumgarten, para servirse solamente de su uso en sentido etimológico, como "doctrina general de la sensibilidad". "Los alemanes —escribe Kant en la Crítica de la razón pura - son los únicos que emplean ahora la palabra "estética", para designar, por medio de ella, lo que otros llaman crítica del gusto (Kritik des Geschmacks) ${ }^{22}$ ».

La tarea de fundamentar esta Kritik des Geschmacks la consideraba Kant en 1781 como vana e infructuosa (vergeblich). Nueve años más tarde sin embargo la aborda como una parte fundamental de su Crítica del Juicio.

Nos encontramos por tanto ante una situación peculiar. En la Crítica de la razón pura se trata de establecer las condiciones de posibilidad de la metafísica como ciencia. Esta mostrará que la metafísica sólo es posible como ciencia, a condición de convertirse a sí misma en Crítica de la razón pura.

Según los conceptos que ofrecemos en este libro, la metafísica es la única, entre todas las ciencias, que puede prometerse semejante perfección, y ello en poco tiempo y con poco, aunque concentrado, esfuerzo. De tal manera, que no queda a la posteridad sino la tarea de organizarlo todo de forma didáctica según sus designios, sin poder aumentar el contenido de la ciencia en lo más mínimo. En efecto, la metafísica no es más que el inventario de todos los conocimientos que poseemos, sistemáticamente ordenados por la razón pura $^{23}$.

Con ello la filosofía misma se convierte en crítica. No es objeto de este trabajo el mostrar cómo Kant convierte la Metafísica en una verdadera ciencia, al transformarla en Crítica de la razón pura. Pero sí que lo es el insistir en que, con esta transformación de la filosofía en crítica, luego no va a ser nada fácil establecer la distinción entre crítica filosófica, crítica artística y literaria, y crítica social, política y económica.

Para Kant, la oposición fundamental a la actitud crítica es, por un lado, la actitud dogmática y, por otro, la actitud escéptica. Si la Crítica de la razón pura alcanza así el éxito prometido, de algún modo la Crítica de la razón práctica se corresponde

$22 K r V, \mathrm{~A} 21, \mathrm{~B} 35$, nota k; trad. p. 66.

${ }^{23} \mathrm{KrV}$, Prólogo a la primera edición. 
con el intento de establecer una ética como ciencia. Posiblemente la Crítica del Juicio sea el intento de establecer las condiciones de posibilidad de una estética como ciencia, pero de la estética entendida como crítica del gusto.

\section{La Estética como ciencia}

Por analogía con la CRÍtTCA DE LA RAZÓN PURA, en la que se plantea el problema de cómo es posible la Metafísica como ciencia, podríamos pensar que Kant se plantease indirectamente en la Crítica del Juicio el problema de cómo es posible, si es que es posible, una Estética como ciencia. Y es cierto que, en la Kritik der Urteilskraft (1790), Kant se ocupa de cuestiones tales como las de la fundamentación de nuestros juicios de gusto, del problema de lo bello y de lo sublime, así como de sugerirnos diversas clasificaciones posibles de las Bellas Artes.

Gilles Déleuze lo afirmaba explícitamente en un seminario sobre Kant, impartido en la universidad de Vincennes el año 1978:

Hay una disciplina particular que va a ser radicalmente fundada por la Crítica del Juicio, a saber, la fundación de toda estética posible. La estética ha comenzado a existir como cosa diferente de la historia del arte con la Crítica del Juicio ${ }^{24}$.

Todo ello nos permitiría efectivamente pensar que Kant se ocupa en este libro de cuestiones de estética. Lo que es correcto. Y, sin embargo, al respecto, es necesario hacer dos importantes matizaciones. La primera, es que Kant no se plantea aquí en ningún caso el problema de cómo es posible la Estética como ciencia. Pues para él la Estética, tal como aparece en la Crítica de la razón pura, ya es una ciencia, entendida como doctrina trascendental de la sensibilidad. Pero esta Estética trascendental sólo se ocupa de las condiciones puras a priori de la sensibilidad, es decir, del espacio y del tiempo, pero no se interesa en absoluto por las cuestiones del gusto, ni por la belleza ni por la sublimidad ni tampoco por las clasificaciones de las artes. Y, por tanto, si Kant se ocupa en la Crítica del Juicio de alguna ciencia relativa a las cuestiones de gusto, no es propiamente de una estética, sino de una crítica: la crítica artística y literaria, a la que él denomina Kritik des Geschmacks.

La segunda cuestión, que es importante matizar, es que la Crítica del Juicio no se ocupa tan sólo de la fundamentación de nuestros juicios de gusto, sino también del

${ }^{24}$ Gilles Deleuze, Cuatro Lecciones Sobre Kant, dictadas entre marzo y abril de 1978, Tercera lección (28/03/78), Escuela de Filosofía Universidad Arcis, disponible en línea en: https://www.ddooss.org/articulos/textos/deleuzze.pdf [consultado el 9/10/2017]. 
problema de la teleología en la naturaleza. Lo que produce en este libro una cierta sensación de extrañeza. Como si se tratase en realidad de dos libros diferentes: el primero dedicado a la estética y el segundo a la teleología.

Pero también es cierto que Kant se plantea en la Crítica del Juicio el problema de cómo es posible o de cómo sería posible la crítica como ciencia. Pensando aquí la crítica como "crítica artística y literaria". Ello podría querer decir que Kant se está enfrentando aquí a la cuestión de posibilidad de las poéticas clasicistas, características del s. XVII, como la de Boileau, que establecían normas relativas al buen gusto y a cómo se debe componer. Como si la composición teatral, poética o musical pudiese reducirse a reglas. Pero Kant no habla de la poética, sino propiamente de la crítica. Y esto es importante.

Y lo cierto es que, también a la pregunta de cómo es posible la crítica como ciencia, Kant ya ha contestado en la Crítica de la razón pura. La crítica es posible como la ciencia de los elementos puros a priori del conocimiento. Es decir, como filosofía o, mejor dicho, como Crítica de la razón pura. De modo tal que la crítica se identifica con la filosofía y la filosofía con la crítica. Por eso todo el programa filosófico kantiano se autodenomina "criticismo". Pero aquí, en la Kritik der Urteilskraft, la cuestión de la crítica añade un pequeño matiz: ¿cómo es posible la crítica (artística y literaria) como ciencia? Y esta es una cuestión que, sin duda, es equivalente a la de ¿̨cómo es posible una Estética como ciencia? Pues ya Baumgarten había identificado la Estética con la crítica y había sentado los principios de una lógica del gusto. "Lógica del gusto" es también el nombre que le da Edmund Burke a su Investigación filosófica sobre el origen de nuestras ideas de lo bello y lo sublime. Kant se ocupa aquí de lo bello y de lo sublime, pero no se atreve a hablar de una lógica del gusto, sino tan sólo de su crítica, y de las condiciones de posibilidad de la misma como ciencia.

El parágrafo 34 de la Kritik der Urteilskraft parece tener un título desolador para estas pretensiones de la crítica: "No es posible principio alguno objetivo del gusto" —afirma- Y Y al respecto Kant se despacha con bastante ironía: "A pesar de que los críticos, como dice Hume, pueden disputar más espaciosamente que los cocineros, tienen sin embargo la misma suerte que éstos". En efecto, ya en el parágrafo anterior ha quedado claro que "el juicio de gusto no puede en modo alguno ser determinado por base de demostración, exactamente como si fuera meramente subjetivo". Y ello parece condicionar ya claramente las pretensiones de toda crítica (artística y literaria) que aspire a alcanzar el camino seguro de la ciencia. Pues no parece que haya posibilidad alguna de que la crítica pueda transformar sus juicios y apreciaciones subjetivas en reglas y normas objetivas de gusto, universales - como las proposiciones de la lógica y de la matemática- y válidas para todos los hombres. 
Y, sin embargo, el propio Kant nos va a proponer una doble solución para la crítica que, por un momento, nos puede dejar desconcertados. Pues, para nuestra sorpresa, nos dirá que la crítica (artística y literaria) no es sólo posible como ciencia, sino también como arte. "Así, la crítica misma del gusto es sólo subjetiva en consideración de la representación mediante la cual un objeto nos es dado; es, a saber: el arte o ciencia de traer a reglas la relación recíproca del entendimiento y la imaginación” 25 .

No debemos desesperar por tanto con respecto a las condiciones de posibilidad de una crítica (artística y literaria) como ciencia. Aunque no se pueda demostrar a priori el juicio de gusto, no por ello debe dejar el crítico de razonar al respecto. Pues ello también constituye un "arte". Ella es arte — dice Kant— cuando muestra esta relación recíproca entre el entendimiento y la imaginación sólo por medio de ejemplos (Sie ist Kunst, wenn sie dieses nur an Beispielen zeigt). Y, a pesar de ello, Kant no niega tampoco la posibilidad de una crítica (artística y literaria) pensada como ciencia. "Ella es ciencia cuando la posibilidad de semejante juicio la deduce de la naturaleza de esa facultad, como facultad del conocimiento en general" (sie ist Wissenschaft, wenn sie die Möglichkeit einer solchen Beurteilung von der Natur dieser Vermögen als Erkenntnisvermögen überhaupt ableitet). Con esta última sola, como crítica trascendental, tenemos aquí que ocuparnos. Debe desarrollar y justificar el principio subjetivo del gusto, como un principio a priori del Juicio" ${ }^{26}$.

Sucede aquí lo mismo que con la Metafísica en la Crítica de la razón pura. La única posibilidad que tiene de alcanzar el camino seguro de la ciencia es la de convertirse a sí misma en Crítica de la razón pura. Lo mismo le pasará a la Estética, entendida como crítica artística y literaria. La única posibilidad que tiene de convertirse en ciencia es convertirse a sí misma en Kritik der Urteilskraft.

Se da de este modo en Kant una doble identificación de la filosofía con la crítica y de la crítica con la filosofía. La única posibilidad de la crítica artística y literaria de alcanzar el camino seguro de la ciencia es la de convertirse a sí misma en Crítica de la facultad de juzgar, es decir, convertirse a sí misma en filosofía. Exactamente lo mismo que consideraba Adorno.

\section{Marx y la crítica}

Sorprende en eSTe contexto presentar a Marx como teórico de la Estética. Porque de algún modo su pensamiento supone no solo el final de la filosofía, sino con

\footnotetext{
${ }^{25}$ K. U. $\$ 34$.

${ }^{26}$ Id.
} 
ella también de toda estética. De hecho, el pensamiento marxista muestra con rotundidad que toda la filosofía no es más que una superestructura ideológica (como el arte y como la religión) al servicio de los intereses de la clase dominante. Por eso el pensamiento de Marx se suele caracterizar como una evolución, de la crítica de la ideología, a la crítica de la economía política. En esta evolución sin embargo lo que más sorprende es la constancia y la permanencia del concepto de crítica.

De algún modo la tradición crítica que Marx invoca es la del llamado criticismo kantiano. Es decir, aquella tradición que convierte a la filosofía en crítica. En la medida en que se mantiene fiel a dicha tradición, sigue siendo también y todavía un filósofo.

Pretender sin embargo que la crítica política y económica marxista tenga algo que ver con el concepto de crítica artística y literaria puede resultar ciertamente extraño. Sin embargo, más extraño y más sorprendente resulta el hecho de que la filosofía marxista, después de haber mostrado contundentemente que tanto el arte, como la religión, como la propia filosofía, no son sino modos superestructurales de legitimación de la ideología dominante, reaparezca en el s. XX una poderosísima filosofía del arte, en el pensamiento de autores marxistas como Lukács, como Benjamin, como Adorno, como Bloch o como Marcuse.

Tratar de pensar esta conexión nos permitiría entender las ocasionales referencias hechas por Marx al arte y a la literatura no como meros excursus intempestivos en los problemas de la Estética, sino como la forma misma de manifestarse de su filosofía crítica,

Podemos entender entonces la evolución del pensamiento de Marx como un tránsito de la crítica de la ideología a la crítica de la economía política. La publicación de sus distintos libros permite confirmar esta evolución, y además él mismo nos lo corrobora, en el célebre prólogo a su Contribución a la crítica de la economía política, publicada en Londres en 1859.

Así, mientras que sus primeros libros tenían títulos tales como Crítica de la Filosofía del Derecho de Hegel (1844), La ideología alemana (1845), La sagrada familia (1845) o Miseria de la Filosofía (1847). Las obras de madurez de Marx, la mencionada Contribución a la crítica de la economía politica (1853) y El Capital, obra culminación de su carrera y subtitulado, como todo el mundo sabe, Crítica de la economía política (1867-1894). En toda su obra es notable sin embargo la persistencia del concepto de "crítica". ¿Qué significa dicho concepto que caracteriza de este modo toda la evolución de la filosofía marxista?

Para explorar esta cuestión, vale la pena confrontar dos textos de Marx de una y otra época. Analizaremos así, en primer lugar, algunos elementos de La Sagrada Familia, cuyo humorístico subtítulo es nada menos que Crítica de la crítica crítica, 
contra Bruno Bauer y consortes. Y nos ocuparemos, en segundo lugar, del mencionado prólogo a la Contribución a la crítica de la Economía política, en la que Marx hace un recorrido por su propia trayectoria intelectual.

En el primer caso, es evidente la sátira que, del concepto de crítica, identificada con la filosofía, habían hecho algunos ideólogos alemanes, como Bruno Bauer y sus hermanos, Edgard y Egbert, editores de la Gaceta literaria (Literaturzeitung), publicada en Berlín hacia 1844. Es interesante señalar que esta sátira, contra el concepto de crítica, se produce específicamente en el contexto de una revista de crítica literaria y que además se formula jocosamente como tal. Para Marx y Engels, la crítica de los hermanos Bauer "da a la deformación de la realidad, por medio de la filosofía el ritmo terminado de una comedia muy documental" ${ }^{27}$. La cómica y burlona crítica de dicha comedia es el objetivo aquí de la crítica filosófica de Marx y Engels. "La Literaturzeitung — escriben - nos surte de los materiales que pueden servir para hacer comprender, incluso al gran público, las ilusiones de la filosofía especulativa. Tal es la finalidad de nuestro trabajo" 28 .

Característicamente este trabajo se centra primero en una sátira despiadada de todos y cada uno de los colaboradores de la Gaceta literaria y en una crítica demoledora de sus procedimientos y sus métodos. Así la crítica se divierte, en primer lugar, en deslegitimar el propio nombre de la crítica, en cuanto se identifica con la filosofía especulativa. Y por tanto la crítica es aquí, como en Kant, una crítica de la filosofía misma. Pero en realidad su procedimiento no consiste sino en la inversión materialista de la filosofía. Frente a las pretensiones espirituales de la filosofía de los hermanos Bauer, que parece exigir una conciencia superior para la creación, "la crítica crítica —afirman Marx y Engels — no crea nada; el obrero lo crea todo y hasta tal punto que, por las creaciones de su espíritu avergüenza a toda la crítica: los obreros ingleses y franceses pueden testimoniarlo. El obrero hasta crea al hombre" ${ }^{29}$.

De este modo la creación no es aquí entendida como creación artística y literaria, sino como producción social y política. Mientras que los críticos críticos, siguiendo a Hegel, pretenden que la creación es la producción espiritual, Marx y Engels, siguiendo a Feuerbach señalan la "necesidad de la filosofía de descender de la esfera de la especulación, hasta la profundidad de la miseria humana" 30 .

Por eso el giro que le otorgan a su crítica de la filosofía especulativa es característicamente el giro de la inversión materialista del pensamiento hegeliano, llevada a cabo

\footnotetext{
${ }^{27}$ Karl Marx y Friedrich Engels, La sagrada familia, trad. de Carlos Liacho, Akal, Madrid, 1977, prólogo, p. 19.

${ }^{28}$ Id.

${ }^{29}$ Id. p. 33.

${ }^{30}$ Id. p. 54.
} 
por Ludwig Feuerbach. Así "la crítica crítica les enseña [a los obreros] que ellos dejan de ser asalariados si, en el pensamiento, suprimen la idea del trabajo asalariado y, conforme a esta imaginación extraordinaria, no se hacen pagar más por sus personas. Idealistas absolutos, entidades puramente etéreas, después pueden vivir naturalmente de la emanación del pensamiento puro. La crítica crítica les enseña que suprimen el capital real dominando, mediante el pensamiento, las categorías del capital" ${ }^{31}$.

El segundo concepto de crítica en Marx no es cualitativamente diferente de este primero. Lo único que cambia es su objeto. Mientras que en su juventud Marx satirizaba a los ideólogos alemanes, herederos de Hegel, en su madurez lo que criticará serán las doctrinas económicas de Adam Smith y David Ricardo.

La única diferencia es que Marx pretende encontrarse ahora en el umbral de la ciencia. Es decir, como en Kant, Marx pretende llevar a la filosofía por el camino seguro de las ciencias. Por eso, tal vez valga la pena hacerse una mejor idea de esta "concepción científica de la crítica", que dio en llamarse precisamente Crítica de la economía politica.

Esta concepción de la crítica aparece claramente explicitada en el prólogo de la Contribución a la crítica de la economía política de 1859. En dicho prólogo Marx trata de justificar la seriedad y la dignidad científica de su trabajo y por eso hace un interesante recorrido por su propia trayectoria vital. De esta caracterización de su método podemos extraer las siguientes observaciones:

1.- En la producción social de su vida, los hombres entran en determinadas relaciones, independientes de su voluntad. 2.- Estas relaciones de producción constituyen la estructura económica de la sociedad. 3.- Sobre esta estructura económica se erige la superestructura jurídica y política, a la que corresponden determinadas formas de conciencia social. 4.- No es la conciencia de los hombres la que determina su ser social, sino su ser social lo que determina su conciencia. 5.- En cierta fase de su desarrollo, las fuerzas productivas entran en conflicto con las relaciones de producción (relaciones de propiedad). 6.- Se abre así una época de revolución social. 7.- Al cambiar la base económica se transforma toda la superestructura. 8.Es preciso distinguir entre la transformación material —que se puede estudiar con la exactitud de las ciencias naturales- de las condiciones de producción económica y las formas jurídicas, políticas, religiosas, artística o filosóficas. Formas ideológicas bajo las cuales los hombres toman conciencia de este conflicto e intentan resolverlo. 9.- Del mismo modo que no se puede juzgar a un individuo por lo que piensa de sí mismo, tampoco es posible juzgar a semejante época por su propia conciencia (i. e. por su arte, su religión o su filosofía). Es preciso al contario juzgar esta conciencia

31 Id. p. 68. 
por las contradicciones de la vida material, por el conflicto existente entre las fuerzas productivas y las relaciones de producción.

De este modo, la crítica establece el modelo crítico, de cómo se debe juzgar. La crítica de la ideología termina declarando a la propia filosofía como una falsa conciencia. Y la crítica de la economía política termina mostrando que no solo la filosofía, sino también el arte, la religión, el Estado y el derecho son parte de esa superestructura ideológica de legitimación del estado de cosas dado. Frente a ello, la crítica, como en Kant, trata de salvarse de esta perspectiva y de alcanzar el camino seguro de la ciencia.

\section{Coda}

UNO PUEDE MOSTRAR CIERTA SORPRESA y estupor cuando contempla no solo el resurgir de la filosofía entre los autores de la llamada Escuela de Frankfurt, sino sobre todo su inquietante deslizamiento hacia la Estética, como si ello supusiera el reconocimiento del fracaso de la filosofía en sus compromisos emancipatorios y una especie de fuga o de apartamiento de lo real. El marxismo consideraba al arte y a la filosofía como mera ideología (o falsa conciencia) y el hecho de que, durante el s. $X X$, reaparezca con fuerza una filosofía marxista del arte, en la obra de Benjamin, de Adorno o de Marcuse puede parecer una paradoja.

Es cierto que Adorno y Horkheimer, con los años, se fueron retractando de muchas de las consignas revolucionarias de su juventud, y que, a diferencia de Lukács, siempre mantuvieron una prudente distancia con respecto a la práctica política. Sin embargo, si su filosofía se identifica con lo que ellos dieron en llamar "Teoría crítica", su retorno a la filosofía no solo no era contrario a la teoría y a la práctica marxistas, sino más bien la continuación del modelo de crítica, desarrollado por el propio Karl Marx. Que este modelo implicaba, suponía y contenía un componente de crítica artística y cultural tal vez supuso una cierta sorpresa para alguno, pero es algo que Adorno defendió con la más absoluta convicción.

En su Teoría estética, el libro póstumo que se publicó un año después de su muerte, en 1970, Adorno defendió explícitamente esta idea de la crítica, a la que identificó, sin ningún tipo de reparos, con la propia filosofía. Por eso pudo afirmar "la genuina experiencia estética tiene que convertirse en filosofía o no es absolutamente nada" 32 .

32 Theodor W. Adorno, Teoría estética, trad. de Fernando Riaza, revisada por Francisco Pérez Gutiérrez, Taurus, Madrid, 1971, p. 
En un célebre pasaje, titulado "Contenido de verdad de las obras de arte", expresa Adorno esta íntima unidad entre Estética y filosofía: "El contenido de verdad de las obras de arte es la solución objetiva del enigma de cada una de ellas. Al tender el enigma hacia la solución, está orientando hacia el contenido de verdad. Pero ésta sólo puede lograrse mediante la reflexión filosófica. Esto y no otra cosa es lo que justifica la estética" 33 .

Pero esta justificación de la Estética es, a su vez, lo que legitima la crítica: "La comprensión del contenido de verdad es lo que postula la crítica. Nada se comprende si no se comprende su verdad o falta de verdad, y éste es el tema de la crítica. Hay influencia recíproca entre el desarrollo histórico de las obras por la crítica y el desarrollo filosófico de su contenido de verdad" ${ }^{34}$.

33 Id. p. 171.

34 Id. p. 172. 


\section{ReferenCias Bibliográficas}

Adorno, Theodor W., Teoría estética, trad. de Fernando Riaza, revisada por Francisco Pérez Gutiérrez, Taurus, Madrid, 1971.

Aquino, Tomás De, Suma teológica, ed. bilingüe, BAC, Madrid, 1964.

Aristóteles, Metafísica, ed. trilingüe de Valentín García Yebra, Gredos, Madrid, $2^{\circ}$ ed. revisada, 1982.

Baudelaire, Charles “iPara qué la crítica?”, Salón de 1846, en Salones y otros escritos sobre arte, trad. de Carmen Santos, Visor, Madrid, 1996.

Baumgarten, Alexander Gottlieb, Aesthetica, Traiecti cis Viadrum (Frankfurt del Oder), 1750.

- „Handschrift der Ästhetik“, en Bernhard Poppe, Alexander Gottlieb Baumgarten: Seine Bedeutung und Stellung in der Leibniz-Wolffischen Philosophie und seine Beziehungen zu Kant: Nebst Veröffentlichung einer bisher unbekannten Baumgartens Handschrift, Robert Noske, Borna-Leipzig, 1907.

- Metaphysica, Halae Magdeburgicae (Halle), 3a Ed., 1750.

Clarke, Desmond M., Descartes, A Biography, Cambridge University Press, 2006.

Deleuze, Gilles, Cuatro Lecciones Sobre Kant, Escuela de Filosofía Universidad Arcis, disponible en: https://www.ddooss.org/articulos/textos/deleuzze.pdf [consultado el 9/10/2017].

Descartes René, Discurso del método, trad. de Manuel Machado, Porrúa, Buenos Aires, 1974.

Diderot, Denis y D’alembert, Jean le Rond, Encyclopédie, ou Dictionnaire raisonné des sciences, des arts et des métiers, París, 1751.

Fontenelle, Bernard le Bovier De, "Digression sur les anciens et les modernes" (Paris, 1688) en Robert Shackleton, ed., Entretiens sur la pluralité des mondes et Digression sur les anciens et les modernes, Oxford, 1955.

Horkheimer Max, "La teoría crítica, ayer y hoy", en Sociedad en transición: estudios de filosofía social, trad. de Joan Godó Costa, Península, Barcelona, 1976.

- "Teoría tradicional y teoría crítica” (1937), en Teoría crítica, trad. de Edgardo Albizu y Carlos Luis, Amorrortu Editores, Buenos Aires, Madrid, 1974, tercera reimp. 2003. 
Kant, Inmanuel, Crítica de la razón pura, trad. Pedro Ribas, Alfaguara, Madrid, 1984.

- Crítica del Juicio, trad. de Manuel García Morente, Austral, Madrid, 1977.

Marx Karl y Engels Friedrich, La sagrada familia, trad. de Carlos Liacho, Akal, Madrid, 1977.

DOI: http://doi.org/10.15366/bp2019.21.012

Bajo Palabra. II Época. No21. Pgs: 199-220 